\title{
The Recurrence Rate of Pars Tensa Retraction Cholesteatoma and a New Staging System
}

\author{
Yasuo Mishiro $^{{ }^{*}}$, Hirokazu Katsura ${ }^{1}$, Tadashi Kitahara ${ }^{2}$, Masafumi Sakagami ${ }^{1}$ \\ ${ }^{1}$ Hyogo College of Medicine, Nishinomiya, Japan \\ ${ }^{2}$ Osaka University Graduates of Medicine, Suita, Japan \\ Email: *ymishiro@hyo-med.ac.jp
}

Received November 15, 2013; revised December 10, 2013; accepted January 2, 2014

Copyright (c) 2014 Yasuo Mishiro et al. This is an open access article distributed under the Creative Commons Attribution License, which permits unrestricted use, distribution, and reproduction in any medium, provided the original work is properly cited. In accordance of the Creative Commons Attribution License all Copyrights (c) 2014 are reserved for SCIRP and the owner of the intellectual property Yasuo Mishiro et al. All Copyright (C) 2014 are guarded by law and by SCIRP as a guardian.

\begin{abstract}
Objective: To investigate the cumulative recurrence rate of pars tensa retraction cholesteatoma on the new staging system established by Japan Otological Society (JOS). Materials and Methods: It is a retrospective study and performed in a tertiary and academic center. The series comprised 71 patients with pars tensa retraction cholesteatoma who underwent surgical treatment by a single surgeon between 1994 and 2007. Results: The 10-year cumulative recurrence rate of pars tensa retraction cholesteatoma was $12.1 \%$ overall, $20.0 \%$ in Stage $\mathrm{I}, 14.4 \%$ in Stage II and 6.2\% in Stage III. Conclusions: The JOS staging system for pars tensa retraction cholesteatoma did not reflect the prognosis. The development of a common international staging system for cholesteatoma in the future is desirable.
\end{abstract}

\section{KEYWORDS}

\section{Cholesteatatoma; Pars Tensa; Recurrence Rate; Staging System}

\section{Introduction}

The recurrence rate of cholesteatoma depends upon the follow-up periods, surgical methods, a surgical technique, an extension of cholesteatoma, a method of statistical analysis, etc. [1]. We previously reported that the recurrence rate increased during long-term follow-up and that Kaplan-Meier survival analysis should be used to calculate the recurrence rate [1]. No common staging system has been established to evaluate the extension of acquired cholesteatoma, similar to the UICC TNM classification for cancer. The Japan Otological Society (JOS) proposed a staging system for attic cholesteatoma in 2008 [2], and we reported the recurrence rate of attic cholesteatoma based on this staging system [3]. Furthermore, JOS proposed a revised staging system including attic cholesteatoma and pars tensa retraction cholesteatoma in 2010 [4]. In this article, we describe the recurrence rate of pars tensa retraction cholesteatoma based on this new staging system.

\footnotetext{
*Corresponding author.
}

\section{Materials and Methods}

The series consisted of 71 patients with pars tensa retraction cholesteatoma who underwent surgical treatment by a single surgeon (Y.M.) between 1994 and 2007. Table 1 lists the demographic and clinical characteristic of the patients. The cumulative recurrence rate based on the 2010 JOS staging system was calculated using KaplanMeier survival analysis. Table 2 lists the 2010 JOS staging system of pars tensa retraction cholesteatoma. We used SPSS version19.0J statistical software (SPSS Inc., Chicago, Illinois) to perform the analysis.

\section{Results}

Based on the JOS 2010 staging system, 17 patients (24\%) were included in Stage I, 21 patients (30\%) in Stage II, and 43 patients (47\%) in Stage III. There were 6 recurrences (one residual cholesteatoma and 5 recurrent cholesteatomas). The standard recurrence rate was $8.5 \%$. Table 3 lists the surgical methods for each stage. The overall 10 -year cumulative recurrence rate was $12.1 \%$ 
Table 1. Demographics and clinical characteristics of 71 patients with pars tensa retraction cholesteatoma.

\begin{tabular}{ll}
\hline Gender & $\begin{array}{l}\text { Male: } 35(49 \%) \\
\text { Female: } 36(51 \%)\end{array}$ \\
Median age at surgical treatment & 48 y (5 - 83 y) \\
Median follow-up period & 7.1 y $(0.2-17.4$ y) \\
& Stage I: $17(24 \%)$ \\
Stage & Stage II: $21(30 \%)$ \\
& Stage III: $33(47 \%)$ \\
\hline
\end{tabular}

Table 2. The Japan Otological Society staging system for pars tensa retraction cholesteatoma.

\begin{tabular}{cl}
\hline Stage I & $\begin{array}{l}\text { Cholesteatoma that does not extend beyond } \\
\text { the tympanic cavity }\end{array}$ \\
Stage II & $\begin{array}{l}\text { Cholesteatoma that extends to the attic or the } \\
\text { protympanum beyond the tympanic cavity } \\
\text { Any cholesteatoma causing at least one of } \\
\text { the following complications }\end{array}$ \\
1. Facial palsy \\
2. Intracranial complications \\
3. Labyrinthine fistulae \\
4. Large defect of bony external ear canal \\
5. Profound sensorineural hearing loss \\
6. Total adhesion of the ear drum \\
7. Extension to the petrous apex
\end{tabular}

Table 3. Surgical methods performed at each stage.

\begin{tabular}{ccccccc}
\hline & TCA & ICWT & CWR & $\begin{array}{c}\text { CWR } \\
\text { with MO }\end{array}$ & CWDT & Total \\
\hline Stage I & 5 & 8 & 2 & 1 & 1 & $17(24 \%)$ \\
Stage II & 1 & 9 & 6 & 1 & 4 & $21(30 \%)$ \\
Stage III & 2 & 5 & 6 & 4 & 16 & $33(47 \%)$ \\
Total & $8(11 \%)$ & $22(31 \%)$ & $14(20 \%)$ & $6(8 \%)$ & $21(30 \%)$ & 71 \\
\hline
\end{tabular}

TCA: Transcanal atticotomy; ICET: Intact canal wall tympanoplasty; CWR: Canal wall reconstruction after canal wall down mastoidectomy; MO: Mastoid obliteration; CWDT: Canal wall down tympanoplasty.

(Figure 1). The 10-year cumulative recurrence rate was $20.0 \%$ in Stage I, $14.4 \%$ in Stage II, and $6.2 \%$ in Stage III (Figure 2).

\section{Discussion}

The recurrence rate of cholesteatoma depends upon the follow-up periods, surgical methods, surgical technique, extension of cholesteatoma, method of statistical analysis, etc. [1]. Stangerup et al. [5] compared recurrence rates using several statistical methods. They reported that the recurrence rate varied from $30 \%$ to $67 \%$, and the standard rate showed the lowest recurrence rate. They concluded that the incidence by the risk method (Nelson-Aalen), actual survival analysis, or Kaplan-Meier survival analysis should be used in cases involving censored data. Therefore, we have used Kaplan-Meier analysis in previous articles [1,3] and in this article.

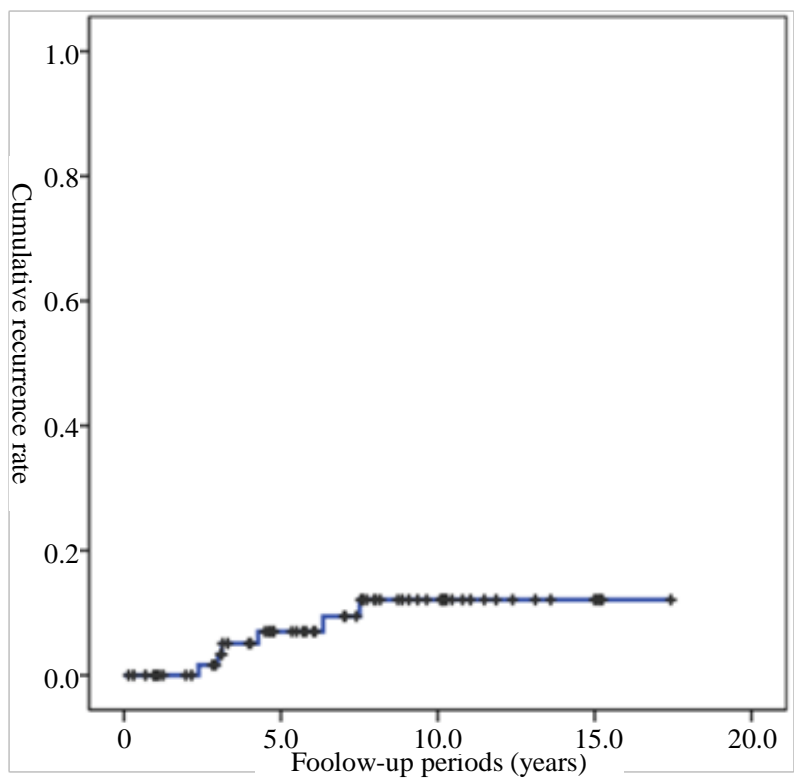

Figure 1. The overall cumulative recurrence rate.

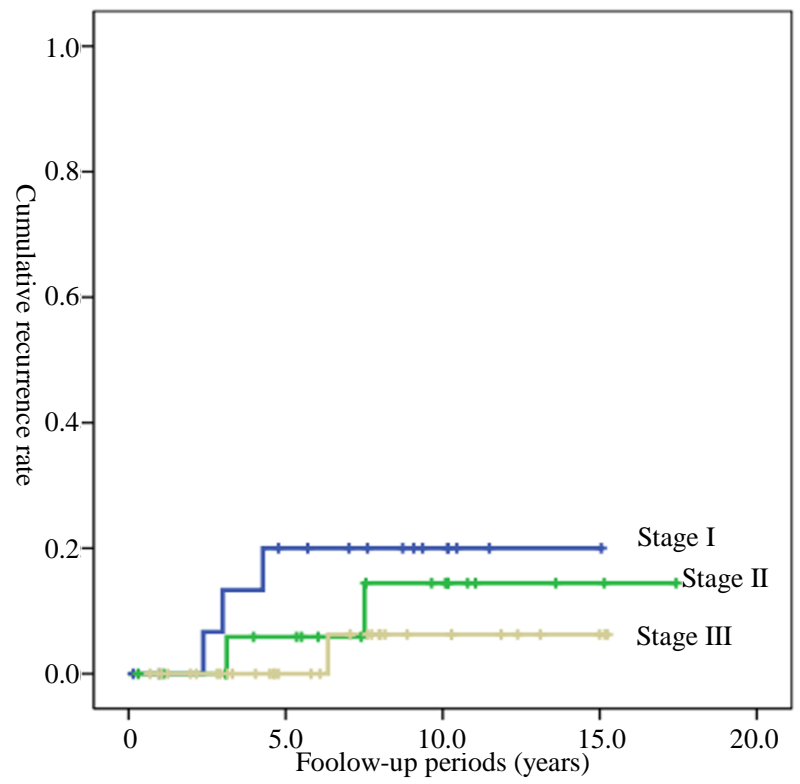

Figure 2. The cumulative recurrence rate of individual stages.

Concerning the staging system of cholesteatoma, Potsic et al. [6] proposed a new staging system for congenital cholesteatoma in 2002. This staging system has been widely used $[7,8]$. However, for acquired cholesteatoma, no common staging system has been developed to evaluate the extension of cholesteatoma, similar to the UICC TNM classification. JOS proposed a new staging for attic cholesteatoma in 2008 [2], and a revised staging system including pars tensa retraction cholesteatoma in 2010 [4]. We previously reported that the 10-year recurrence rate based on the JOS 2008 staging system was 18.6\% overall, 
$0 \%$ in Stage I, 24.6\% in Stage II, and 9.1\% in Stage III, and we concluded that this staging system reflected the prognosis to some extent [3]. However, concerning a new staging system for pars tensa retraction cholesteatoma, Stage I showed the worst prognosis and Stage III had the best prognosis. This is because the rate of canal wall down tympanoplasty (CWDT) was 6\% in Stage I, $19 \%$ in Stage II, and $48 \%$ in Stage III (Table 3). We reported that CWDT showed a better long-term prognosis than intact canal wall tympanoplasty (ICWT) and canal wall reconstruction (CWR) after CWDT [1]. If we use CWDT for every case, the prognosis may improve, but the risk of cavity problems may increase. Therefore, surgical methods should be determined based on the characteristic of each case [1]. Caye-Thomasen et al. reported that the cartilage palisade grafting technique [9] appeared to prevent long-term eardrum retraction [10]. We have also used the cartilage palisade grafting technique for pars tensa retraction cholesteatoma. However, the follow-up periods are not long enough to provide for useful discussion in this paper. The 2010 JOS staging system for pars tensa retraction cholesteatoma did not reflect the prognosis. However, the development of a common international staging system for cholesteatoma reflecting the prognosis and indicating the surgical methods is desirable in the future.

\section{Conclusion}

The 10-year cumulative recurrence rate of pars tensa retraction cholesteatoma based on the 2010 JOS staging system was $12.1 \%$ overall, $20 \%$ in Stage I, $14.4 \%$ in Stage II, 6.2\% in Stage III. This staging system did not reflect the prognosis, and the development of a common international staging system for cholesteatoma in the future is desirable.

\section{Acknowledgements}

This study was supported by a Grant-in-Aid for Researchers, Hyogo College of medicine, 2011.

\section{REFERENCES}

[1] Y. Mishiro, M. Sakagami, T. Kitahara, K. Kondo and S.
Okumura, "The Investigation of the Recurrence Rate of Cholesteatoma Using Kaplan-Meier Survival Analysis,” Otology \& Neurotology, Vol. 29, No. 6, 2008, pp. 803806. http://dx.doi.org/10.1097/MAO.0b013e318181337f

[2] Japan Otological Society, “Cholesteatoma Staging System,” Otology Japan, Vol. 18, No. 5, 2008, pp. 611-615.

[3] M. Hashimoto-Ikehara, Y. Mishiro, T. Kitahara and M. Sakagami, "The 10-Year Disease-Free Rate of Attic Cholesteatoma Based on a New Staging System,” Journal of International Advanced Otology, Vol. 7, No. 3, 2011, pp. 289-292.

[4] Japan Otological Society, "Staging of Middle Ear Cholesteatoma,” Otology Japan, Vol. 20, No. 5, 2010, pp. 743-145.

[5] S. E. Stangerup, D. Drozdziewics, M. Tos and A. H. Jenzen, "Recurrence Rate of Attic Cholesteatoma: Different Methods of Estimating Recurrence Rate," Otolaryngology -Head and Neck Surgery, Vol. 123, No. 3, 2000, pp. 283-287. http://dx.doi.org/10.1067/mhn.2000.104666

[6] W. P. Potsic, D. S. Samadi, R. R. Marsh and R. F. Wetmore, “A Staging System for Congenital Cholesteatoma," Otolaryngology-Head and Neck Surgery, Vol. 128, No. 9, 2002, pp. 1009-1012.

http://dx.doi.org/10.1001/archotol.128.9.1009

[7] G. Inoguchi, T. Okuno, Y. Hata, M. Baba and D. Sugiyama, "Congenital Cholesteatoma: Posterior Lesions and Staging System," Annals of Otology, Rhinology, and Laryngology, Vol. 119, No. 7, 2010, pp. 490-494.

[8] H. G. Choi, K. H. Park, S. N. Park, B. C. Jun, D. H. Lee, Y. S. Park, et al., "Clinical Experience of 71 Cases of Congenital Middle Ear Cholesteatoma,” Acta Oto-laryngologica, Vol. 130, No. 1, 2010, pp. 62-67. http://dx.doi.org/10.3109/00016480902963079

[9] J. Heermann Jr., H. Heermann and E. Kopstein, "Fascia and Cartilage Palisade Tympanoplasty: Nine Years Experience," Otolaryngology—Head and Neck Surgery, Vol. 91, No. 3, 1970, pp. 228-241.

http://dx.doi.org/10.1001/archotol.1970.00770040334004

[10] P. Caye-Thomasen, J. Anderson, C. Uzun, S. Hansen and M. Tos, "Ten-Year Results of Cartilage Palisades versus Fascia in Eardrum Reconstruction after Surgery for Sinus or Tensa Retraction Cholesteatoma in Children," Laryngoscope, Vol. 119, No. 5, 2009, pp. 944-952. http://dx.doi.org/10.1002/lary.20195 